\title{
REVISIONES
}

\section{Subjetividad y política: consecuencias para el discurso educativo*}

\author{
Subjectivity and politics: implications for educational discourse \\ Subjetividade e política: implicações para o discurso educacional
}

\author{
Luis Flores, Viviana Sobrero
}

Pontificia Universidad Católica de Chile

\begin{abstract}
RESUMEN
El artículo propone un marco de interpretación para explorar los nexos posibles entre las políticas educativas y la configuración de subjetividades. Tomando como punto de partida los aportes de la fenomenología y la hermenéutica, se presenta una propuesta de análisis que pretende interrumpir las lecturas dicotómicas y reduccionistas de los fenómenos educativos actuales que restringen la política educativa actual a un tema más de "gestión" y de administración de recursos que a un discernimiento sobre la cuestión estratégica, finalidades y sentido de la educación.
\end{abstract}

Palabras clave: subjetividad, discurso, poder, política educativa.

\begin{abstract}
The article proposes an interpretative framework to explore the possible links between educational policies and subjectivities shaping. Considering, as building blocks, the contributions of phenomenology and hermeneutics, it is presented a proposal that aims to disrupt dichotomous and reductionist readings of current educational phenomena; restricting the present educational policy to a theme of "administration" and resource management instead of leading to an insight into the strategically issues, purposes and the real meaning of education.
\end{abstract}

Keywords: subjectivity, discourse, power, education policy.

\section{RESUMO}

Propõe um contexto de interpretação para explorar as possíveis ligações entre as políticas educativas e a configuração de subjetividade. Partindo das contribuições da fenomenologia e da hermenêutica, apresenta-se uma proposição de análise que tenta cessar as leituras e dicotomias reducionistas dos atuais fenômenos educacionais que restringem as políticas educacionais na atualidade a temas mais de "gestão" e administração do que em discernimento sobre questões de estratégias, de finalidades e de sentidos na educação.

Palavras chave: subjetividade, discurso, poder, política educativa.

* $\quad$ Este artículo se ha desarrollado en el marco de la investigación del Proyecto Fondecyt №1080218, Gestión del conocimiento y reforma del pensamiento en educación. Reformulaciones epistemológicas y sociopolíticas para programas de formación de Profesores. Investigador responsable: Luis Flores. 


\section{INTRODUCCIÓN}

El artículo presenta una propuesta epistemológica que tensiona los supuestos de la filosofía de la conciencia y del positivismo a partir de la incorporación de diferentes aportes provenientes de la fenomenología y la hermenéutica, para abrir un campo perceptivo que permita pensar los nexos posibles entre la subjetividad, la política y la educación.

Explorar los nexos posibles entre las políticas educativas y la configuración de subjetividades nos exige además problematizar los supuestos epistemológicos que sustentan la filosofía de la conciencia que, como legado de la Ilustración, aún tienen fuerte presencia en la teoría social y en las investigaciones educativas actuales ${ }^{1}$. Este trabajo estará dividido en dos momentos: en la primera parte de este trabajo presentamos las principales vertientes epistemológicas y teóricas desde donde se configura la noción de subjetividad. Incorporamos aquí, en primer lugar, los aportes de la fenomenología con Husserl, Merleau-Ponty y F. Varela, a partir de los cuales definimos la subjetividad por su condición encarnada, emergente e intersubjetiva. Desde la hermenéutica, proponemos algunas nociones teóricas desarrolladas por Michel Foucault, que permiten analizar las relaciones entre las formas de saber, las formas de poder y las formas de sujeto.

En la segunda parte de este trabajo, se analiza el aporte conceptual que la noción subjetividad entendida desde la teoría política y la hermenéutica puede constituir para pensar la política educativa y los fenómenos educativos en general. En primer término, incorporamos algunos aportes provenientes de la filosofía y la teoría política para pensar la dimensión subjetiva de la política. En particular, el análisis recoge los aportes de Cornelius Castoriadis (1922-1997) y su noción de política como proyecto de autonomía. En segundo lugar, retomamos la noción de discurso -en tanto práctica discursiva- y de subjetividad como "efecto" emergente del conjunto de relaciones de saber-poder, a modo de herramientas conceptuales que sustentan una concepción de educación y de política educativa entendida como prácticas de significación.

Finalmente, desde el marco teórico-epistemológico anteriormente expuesto, proponemos una mirada que pretende interrumpir las lecturas dicotómicas y reduccionistas de los fenómenos educativos actuales que restringen la política a un tema de "gestión" y de administración de recursos, más que a un discernimiento sobre la cuestión estratégica, de los fines y sentido de la educación.

\section{LA CUESTIÓN DE LA SUBJETIVIDAD: CONTRIBUCIONES DE LA FENOMENOLOGÍA}

En este apartado se discute la noción de subjetividad en referencia a los vínculos teóricos existentes entre fenomenología, ciencias cognitivas desde la perspectiva de F. Varela y el pensamiento de C. Castoriadis.

\footnotetext{
La filosofía de la conciencia es una denominación referida a la posición filosófica que privilegia y supone la idea de un sujeto y una conciencia trascendental. Para estos pensadores, sea Descartes, Kant o Hegel entre otros, hay una necesidad a priori del pensamiento sobre la "realidad", al extremo de identificar lo real con lo racional, y por tanto al sujeto como conciencia o razón pura.
} 


\subsection{LA SUBJETIVIDAD ENCARNADA}

Uno de los aportes teóricos más relevantes de la fenomenología desde Husserl y luego Merleau-Ponty, consiste en reconocer el cuerpo como lugar de la subjetividad humana. Ahora bien, la noción de cuerpo en este caso no solo alude al cuerpo físico que en alemán se dice Körper, sino sobre todo y fundamentalmente a Leib o sea cuerpo sujeto, propio, vivido. Esta distinción es relevante porque al momento de interpretar el conocimiento como una acción privilegiada del ser humano, no se requiere buscar un fundamento sustancial del mismo, sino que como lo sostiene Varela conocer es también una forma de percibir, razón por la cual la mente no está más situada en la cabeza, o en el pensamiento como suponía Descartes, sino en el cuerpo global del sujeto que percibe. De esta forma, la condición de conocer no se limita a la condición objetiva material del cuerpo sino a la experiencia vivida en relación a una afirmación bien distinta a la del cogito cartesiano que sostenía el pensar en autonomía de la corporalidad; la afirmación fenomenológica de la subjetividad no ya la afirmación de una conciencia pensante sino de la de una conciencia encarnada (Flores, L. 2005).

Por otra parte, la fenomenología propone un desplazamiento de la idea de una conciencia pensante a la idea de una conciencia intencional: La intencionalidad es un movimiento de la conciencia que ahora es siempre en relación "para" un otro. La conciencia es para las cosas y las cosas para la conciencia. En esta relación de reciprocidad fundamental entre el sujeto y el mundo es donde se anida la textura de la subjetividad, más que en los motivos secretos e inconscientes de un yo a priori, soterrado o subliminal.

Si toda conciencia es conciencia de algo, no hay entonces una determinación a priori ni de su contenido ni de una estructura dada, ya que ésta se constituye en relación con el mundo.

\subsection{LA CONDICIÓN INTERSUBJETIVA DE LA SUBJETIVIDAD}

Como lo explicita F. Varela, la conciencia (subjetividad) es un "asunto público", no porque haya un ser social que determine la conciencia, sino porque las raíces de la subjetividad aluden siempre a una acción de inserción en el mundo. La conciencia es, de este modo, referencia a "algo", lo que dicho de otra manera significa sostener que la conciencia se constituye como reciprocidad fundamental: la subjetividad es siempre un acto intersubjetivo.

El ser-para-otro es, desde esta mirada, la condición constitutiva del sujeto. Ser sujeto significa estar y ser parte de una acción social que en sus estructuras de significados múltiples siempre es simbólica. La subjetividad es bajo esta interpretación una acción plural, multiforme, multirreferencial, emergencia, fruto de una acción referida y constituida no solo de los encuentros con los otros, sino también de los quiebres con el otro. El mal entendido y desencuentro con los otros, como les sucede a los personajes de las obras de A. Camus y J.P. Sartre son también formas de intersubjetividad.

\subsection{LA SUBJETIVIDAD ES EMERGENCIA Y RELACIÓN RECÍPROCA CON EL MUNDO}

La subjetividad por tanto es más una relación que una cualidad metafísica, o una propiedad de una conciencia abstracta. La conciencia y por ende la subjetividad, es 
entendida ahora como emergencia en el conjunto de redes intencionales desde las cuales la existencia humana se inserta en el mundo. Nuestra primera experiencia es la experiencia de los otros en los diferentes dominios en que nos configuramos como lenguaje, como historia, como deseo, como posibilidad siempre en relación a otros.

Por tanto la subjetividad no se reduce a un movimiento de pura interioridad o introspección incomunicable y fragmentaria. Aunque no se niega el hecho de que la experiencia humana es siempre irreductible, se pone el énfasis en que la subjetividad es un movimiento de pliegue y despliegue desde las experiencias propias de sujeto (como la encarnación, la temporalidad, la conciencia) lo que muestra que la experiencia de subjetividad es una experiencia vinculante hacia el mundo, que también es concebido como una relación fundamental.

Sin embargo, la subjetividad no es una relación que avance exclusivamente desde el individuo hacia el exterior, porque el lado de "afuera" al sujeto no es absoluto, ni tampoco el sujeto es absolutamente autónomo de la relación en que siempre está inserto. La fenomenología de la subjetividad se estructura, más bien, en movimiento de reciprocidad con el mundo y con los otros.

La subjetividad no es un producto, es creación, es autocreación incesante, en una red de relaciones en que se vinculan en convergencia y emergencia lo social, lo histórico-cultural, lo psíquico, lo orgánico y lo biológico (Castoriadis, 1999). Por otra parte, F. Varela en la formulación de las pautas de las ciencias cognitivas, reitera que la conciencia que para él siempre es encarnada e inserta en el mundo, es también un asunto público. La razón de esta afirmación reside en sostener que la subjetividad es intersubjetiva en la medida en que la relación a un otro es ineluctable. El otro no es otra persona, ni su relación necesariamente binaria, el otro puede ser Dios, la naturaleza, o una comunidad (Varela, 2000: 256).

\subsection{PLIEGUES DE SUBJETIVIDAD (DISCURSO, PODER Y SUBJETIVIDAD)}

La subjetividad en tanto creación incesante se configura en una red de relaciones, proceso que se da siempre en el marco de confrontaciones semióticas y semánticas, esto es, en el marco de relaciones de poder.

La noción de subjetividad entendida como configuración intersubjetiva y emergente, plantea un desplazamiento en la analítica del poder, desde una noción represiva que entiende el poder como soberanía, hacia una noción que centra la mirada en los efectos "productivos" del poder que, al circular a través del conocimiento que ordena el sentido común de la vida cotidiana, define categorías y concibe posibilidades.

Incorporamos en este planteamiento algunas nociones teóricas desarrolladas por Michel Foucault que permiten analizar las relaciones entre las formas de saber, las formas de poder y las formas de sujeto. La noción represiva del poder -que se articula en torno a los supuestos de la filosofía de la conciencia- tiende a conceptuarlo como "algo" que se tiene o se posee para dominar y oprimir. El propósito de estudiar el poder desde esta perspectiva consiste en identificar los actores que lo controlan y detentan, lo que permite introducir una noción de poder como soberanía (Popkewitz \& Brennan, 2002: 31-35).

Esta noción de "poder sobre", mediante conceptos estructurales de agencia o resistencia, adscribe el poder a los actores que tienen legitimidad para tomar decisiones (Estado, organismos internacionales, empresarios, etc.) desde el supuesto de que toda sociedad incluye grupos cuyas prácticas dominan y reprimen a otros grupos. 
El riesgo de esta noción de poder soberano -predominante en buena parte del análisis de investigaciones educativas contemporáneas- es su tendencia a dicotomizar el análisis (incluidos/excluidos; oprimidos/opresores) al concentrarse en identificar las fuerzas estructurales o grupos en disputa como si se tratara de entidades monolíticas.

Una analítica diferente plantea la noción de poder como despliegue y efectos productivos que se distancia de las categorías dicotómicas, proporcionando nuevas claves interpretativas que nos permiten abordar la complejidad de las estrategias cambiantes de producción de subjetividades en las sociedades contemporáneas.

Dicha noción de poder torna relevante una indagación descentrada del sujeto psicológico y de modelos de conciencia. El foco de la mirada se desplaza del sujeto, a las condiciones en las que se configura. Así, los elementos productivos del poder pasan, de centrarse en los actores controladores, a los sistemas de ideas que normalizan y construyen las reglas que organizan la intencionalidad y el propósito en el mundo. Los efectos del poder se exploran en la producción del deseo y en las disposiciones y sensibilidades de los individuos.

Desde esta concepción de poder, Foucault propone la noción de "gubernamentalidad" para analizar la producción social de "mentalidades". El poder, en este último sentido, se halla intrincadamente ligado a las reglas, normas y estilos de razonamiento a través de los cuales los sujetos hablan, piensan y actúan en la configuración de su mundo cotidiano. Pero no somos nosotros los que hemos hecho los sistemas de clasificación incorporados en las reglas y estilos de razonamiento; éstos han sido construidos históricamente y circulan a través de nuestras prácticas cotidianas.

En este sentido, el poder es una práctica material y productiva a través de los efectos que tiene el conocimiento para el orden, la disciplina y la producción de la conducta, antes que por lo represivo, tal como se pone de manifiesto en la noción de soberanía del poder.

El poder ya no es identificado con los gobernantes operando desde lo alto, o vértice de la pirámide social, sino que es explorado desde el conocimiento que circula en los discursos a partir de los cuales los individuos construyen su sentido del "sí mismo" y su relación con los demás.

Desde esta perspectiva, el poder no está fuera del discurso, sino que funciona a través del discurso. Lo que se sostiene aquí es que los discursos configuran horizontes de sentidos que delimitan los márgenes, las posibilidades de emergencia o restricción de las nociones de lo real.

El discurso, desde esta perspectiva, se define por su capacidad de articular objetos heterogéneos (Deleuze, 1987: 76), es analizado así en su singularidad, como lugar de emergencia, donde se articulan los enunciados con acontecimientos extradiscursivos (técnicos, económicos, sociales, políticos). Sin embargo, no es entendido como una mera "expresión" de instancias extradiscursivas. Tampoco constituye un fenómeno que obedece a un juego intralingüístico. Más bien, el discurso es considerado como el lugar donde se aglutina en una unidad un conjunto de fenómenos heterogéneos que de ningún modo estaban destinados "naturalmente" a juntarse. (Terán, O, 1995: 17-18).

Así, esta noción de discurso abre un nuevo campo perceptivo para el análisis, que no centrará la mirada ni en las palabras ni en las cosas referidas, sino en el "y" que las vincula en una relación simultáneamente funcional, contingente y constitutiva.

El centro del análisis discursivo es, entonces, “...el haz de relaciones que el discurso debe efectuar para poder hablar de tales y cuales objetos, para poder tratarlos, nombrarlos, 
analizarlos, clasificarlos, explicarlos, etc. Estas relaciones caracterizan no a la lengua que utiliza el discurso, no a las circunstancias en las cuales se despliega, sino al discurso mismo en cuanto práctica”. (Foucault, 2002: 75-76).

El discurso, entendido como práctica discursiva, es irreductible a la lengua y a la palabra, porque es "algo más" que un conjunto de palabras para designar cosas. Este planteamiento supone un rotundo rechazo a un análisis formalista del lenguaje y del discurso "al servicio del significante" (Foucault, 2004).

En este sentido, Foucault propone:

“...dejar de tratar los discursos como conjuntos de signos (de elementos significantes que envían a contenidos o a representaciones), sino como prácticas que forman sistemáticamente los objetos de que hablan. Es indudable que los discursos están formados por signos; pero lo que hacen es más que utilizar esos signos para indicar cosas. Es ese más lo que los vuelve irreductibles a la lengua y a la palabra. Es ese "más" lo que hay que revelar y hay que describir" (Foucault, 2002: 81).

En tanto asume la imposibilidad de pensar alguna simbolización en "estado natural", esto es, sustraída de la imposición de códigos y del juego de fuerzas, esta perspectiva rechaza la concepción clásica de representación, que se fundamenta en la existencia de un nexo entre sujeto y mundo, establecido por la transparencia de los signos lingüísticos y la función normativa del lenguaje. Si no hay un nexo transparente, a priori, entre las palabras y las cosas, los discursos ya no pueden ser considerados como entrecruzamiento de una realidad y una lengua; de un léxico y de una experiencia.

Así, el análisis de los discursos que propone Foucault introduce una verdadera ruptura respecto de la tradición filosófica y lingüística, pues no se propone analizarlos como expresión del pensamiento de un sujeto o el reflejo de una realidad determinada.

Para esta perspectiva, los discursos no son algo que un sujeto expresa o dirige conforme a una intencionalidad o deliberación, sino la puesta en juego de un conjunto de reglas anónimas que conforman restricciones y posibilidades, con arreglo a las cuales suelen ser enunciados, transmitidos, transcritos, escritos, legitimados o rechazados.

En este sentido, las prácticas discursivas no son pura y simplemente modos de fabricación de discursos. Ellas toman cuerpo en el conjunto de técnicas, de las instituciones, de los esquemas de comportamiento, de los tipos de transmisión y de difusión que, a la vez, las imponen y las mantienen (Foucault, en Castro, 2004: 94). Estas instancias exteriores fijan límites a los discursos: No se puede decir cualquier cosa, en cualquier tiempo y lugar, porque existe un conjunto de condiciones de posibilidades y de imposibilidades para la producción discursiva (Foucault, 2002).

En consecuencia, el análisis discursivo consistirá en una indagación en torno al haz de relaciones que definen el horizonte de significación y la condición de emergencia y aparición histórica de los objetos de los que habla.

A partir de estas consideraciones, el discurso será entendido como una práctica que antes que reflejar, constituye; que produce y prescribe, antes que describir. En este sentido, lejos de verse como mera retórica, será analizado como texto que configura significados y convicciones, adscribe reglas y comportamientos y produce identidades.

Pensados así, los discursos constituyen modos de narrar y de dar sentido a lo que inquieta; constituyen maneras de atribuir forma y significado a las percepciones de 
imágenes, constituyen modos de dar legitimidad y hacer verdadero lo que no tiene sentido. Para esta perspectiva, resulta relevante la contribución del planteamiento deleuziano respecto de la producción de subjetividad, a partir de la lógica de sentidos que configuran los discursos. El estatuto de verdad de los discursos, y sus maneras de relacionar las cosas y las ideas, se dan -en su planteamiento- por la instauración y repetición de principios de semejanzas, y no porque tales principios de semejanza antecedan a las relaciones posibles. Es la relación entre componentes diferentes la que funda "la comunidad de lo que no tiene nada en común", por tanto, desde esta mirada no sería la subjetividad la que produce asociaciones, sino las asociaciones las que producen subjetividad (Pardo, 1997).

Los principios de semejanza entre ideas y objetos son producidos a través del ejercicio de la lógica discursiva. La repetición de esta lógica instaura un estatuto de verdad que legitima ciertos modos de relacionar cuerpos, hechos, ideas y objetos. Estas formas de relación no surgen porque haya principios de semejanza verdaderos que las antecedan, sino que estas formas de relación producen una determinada subjetividad y modos de vida que viven esos principios como verdaderos. La subjetividad, de ese modo, se constituye de efectos de producción de sentido, de los efectos de las relaciones producidas mediante una determinada lógica que ella misma acciona (Farina, 2005).

La cuestión de configuración de subjetividad se entiende así como práctica que constituye modos de ver y nombrar las formas de experiencia de los sujetos. En este contexto, la producción de sentido se entiende como una constitución de una narrativa sobre lo que le pasa al sujeto, que deriva de una práctica del saber. Las formas de esta narrativa mediante las que el sujeto produce sentidos son decisivas para su experiencia, pues es esa narrativa la que en cierto modo produce la experiencia misma.

La repercusión del análisis sobre la producción de subjetividad y de los modos de vida tiene que ver con las formas de producción de las narrativas a través de las cuales los sujetos hacen visible y comprensible la experiencia, y a través de las cuales se hacen visibles a sí mismos en el mundo.

Deleuze establece una distinción entre dos planos posibles de experiencia: las experiencias discursivas y las experiencias como acontecimiento (Morey en Farina, 2005: 127). Las experiencias discursivas se configuran en un plano horizontal del sentido, donde cada momento se justifica por otro que le sigue, y por el que le antecedió. Este tipo de experiencia se articula como los planos de un discurso, como los planos de un curso que nos lleva de un lugar anterior a otro posterior. La experiencia de la horizontalidad funciona como las relaciones que articulan y agregan las cosas e ideas por principios de semejanza. Este tipo de relaciones legitiman la lógica del sentido por una experiencia de la repetición que se teje con objetos e ideas.

En cambio, en otro plano, en un plano vertical, se puede constatar una experiencia de otro orden. La experiencia vertical no es discursiva, porque acontece fuera de las relaciones lógicas, incorporando lo paradójico y el sinsentido. La experiencia vertical tiene que ver con la irrupción de un acontecimiento fuera del sentido, con una fractura del sentido en las relaciones sobre las que se ampara la subjetividad. Lo que se abre a través de la experiencia como acontecimiento, es un campo de potencias que irrumpe en las formas de relación consolidadas, dando lugar a lo inédito. 
El pensamiento deleuziano se interesa por la experiencia como acontecimiento, se interesa por la fuerza del acontecimiento que desterritorializa los campos del sentido, que afecta la lógica del sentido y del orden sensible.

Lo que interesa analizar, entonces, no es la afirmación o la negación de la producción de sentido, pues la subjetividad no vive fuera del sentido, fuera de las referencias que le dan sentido a la realidad. Lo que interesa considerar es el modo cómo se produce sentido, es prestar atención a las formas en que se produce, para que el sentido no preceda a la experiencia y condicione sus direcciones y modalidades.

\section{SUBJETIVIDAD, POLÍTICA Y EDUCACIÓN}

En la segunda parte de este trabajo, se discute el aporte conceptual que la noción subjetividad, entendida desde la teoría política y la hermenéutica puede constituir para pensar la política educativa y los fenómenos educativos en su conjunto.

\subsection{LA POLÍTICA COMO PROYECTO DE AUTONOMÍA}

Desde un planteamiento que pone en discusión la ontología heredada, por su concepción de ser como fundamento, Castoriadis propone pensar la sociedad como autocreación que se manifiesta a través de formas de ser sin equivalentes, modelos, ni causas en el mundo presocial (Castoriadis, 1999).

Tomando como punto de partida la dimensión histórico-social como uno de los dominios del hombre, el filósofo desarrolla un modo de entender la historia como creación ontológica, esto es, como autodespliegue y autocreación permanentes de la sociedad en el tiempo y en el espacio, frente a lo cual, las sociedades encuentran unidad y cohesión en su "institución global". La palabra institución está tomada aquí en su sentido más amplio y radical: comprende normas, valores, lenguaje, instrumentos, procedimientos y métodos que orientan y dotan de sentido las acciones cotidianas de los individuos en una comunidad.

Esta unidad es la cohesión interna que produce la complicada e inmensa red de significaciones de carácter histórico, colectivo, impersonal y anónimo que atraviesan, orientan y dirigen toda la convivencia social. Dichas significaciones son imaginarias -no racionales, ni reflejo de una realidad-y resultan efectivas en tanto son compartidas y otorgan sentido a las experiencias de los sujetos en el mundo, determinando lo que es real y lo que no lo es (Castoriadis, 2003).

En el marco de estas consideraciones, Castoriadis define la política como la expresión del proyecto de autonomía de una sociedad, en tanto actividad que no acepta pasiva y ciegamente las significaciones instituidas, sino que las vuelve a cuestionar (Castoriadis, 1999). Así, el proyecto de autonomía -que sólo es posible en tanto proyecto colectivo- es el movimiento histórico de los sujetos por arribar a una autoinstitución de la sociedad, teniendo como sentido último darse la propia ley.

Esta noción de política como proyecto de autonomía, en tanto asume la indisociabilidad del sujeto (la psique) y la sociedad, constituye una categoría epistemológica que nos permite inquirir en los nexos posibles entre los discursos de política educativa y la producción de subjetividades sociales. 
En este sentido, la subjetividad no es una materia prima anterior a la vida social, sino más bien una configuración cultural, relacionada al modo en que se organiza la sociedad $\mathrm{y}$, en especial, al modo en que la política instituye esa organización social (Lechner, 2002).

Desde una concepción que entiende que no existe un individuo en sí, esto es, fuera del contexto histórico social en el cual actúa y participa, Castoriadis plantea que la estructura psicosocial de todo sujeto se configura solo en la convivencia. El sujeto es comprendido aquí como ser relacional que no se agota en su racionalidad. Se trata de una perspectiva que asume que los individuos y grupos son producto de un proceso de socialización y que su existencia supone la preexistencia de una sociedad instituida. Así, la complicada red de significaciones sociales que constituyen la institución imaginaria de la sociedad mantiene su cohesión y unidad, no tanto por coerción, como por su capacidad para suscitar adhesión y legitimidad por parte de los individuos que la conforman.

Castoriadis caracteriza estas significaciones como imaginarias y sociales, ya que se sustentan en la creación y existen solo si son instituidas y compartidas por una colectividad impersonal y anónima. Entre dichas significaciones se encuentran el Estado, la polis, la nación. Se trata de significaciones que la psique no podría producir por sí sola sin el conjunto. Su efectividad depende de su capacidad de dotar de significación y sentido a todas las acciones que involucra la convivencia humana. Precisamente, una de las tareas de la política es producir y reproducir el orden simbólico donde la acción colectiva tiene sentido. Es a través de las significaciones imaginarias que la política delimita el campo no solo de lo que está a disposición de la voluntad política, sino también el campo de lo posible, de lo deseable y de lo pensable (Lechner, 2002: 25).

El propio Max Weber propondrá para el estudio de la política la consideración de su dimensión poética, es decir, del modo como la palabra política abre mundos posibles de experiencia colectiva. La definición weberiana de la política enfoca justamente la dimensión de la vida colectiva donde el orden social plantea la legitimación del sistema de liderazgo y de la producción de creencias que lo funda, tema que resulta crucial para la política en las modernas democracias representativas occidentales (Pérez, 2002: 182). En la medida en que su legitimidad no se salda por la referencia a algún principio extrasocial, el orden democrático requiere una matriz simbólica capaz de producir la creencia en un estado de cosas y la disposición para la acción, como resultados estratégicos de las imágenes y narrativas configuradas en el campo político. Así, lejos de agotarse en una "buena gestión", la política tiene como una de sus tareas fundamentales hacer que las personas se experimenten a sí mismas como sujetos sociales, esto es, como constructores activos del mundo en que habitan. Sin embargo, una de las tesis centrales que expone Castoriadis sostiene que casi todas las sociedades humanas son instituidas dentro de la heteronomía, esto es, en la ausencia de la autonomía: Los sujetos atados a un mito -desconocido por ellos como tal- atribuyen un origen extrasocial a las leyes que los gobiernan, como si no fuera obra humana, como si todo fuera instituido, perdiéndose la noción de la capacidad instituyente del colectivo (Castoriadis, 1999). El ocultamiento de la autoinstitución -esto es, de la autocreación de la sociedad- y de su autoalteración permanente, constituye para Castoriadis las dos caras de la heteronomía que, en definitiva, lo que consigue ocultar es la fuente del poder que solo existe en el conjunto. 


\subsection{POLÍTICA EDUCATIVA COMO PRÁCTICA DE SIGNIFICACIÓN}

Estas conceptualizaciones que dan primacía al discurso en la configuración de lo social y del sujeto, impactan en el modo de entender las políticas educativas ${ }^{2}$ (Popkewitz \& Brennan, 2002: 25). Esta perspectiva se distancia tanto de las lecturas tecnicistas de la educación, caracterizada por sus categorías continuistas que niegan su carácter histórico (variable, mutable) y social (construido, polifónico), como de las perspectivas sociocríticas que, en gran parte, permanecen prisioneras de una concepción "soberana" del poder, que instala categorías dicotómicas para explicar las relaciones sociales.

En tanto la vida social no puede entenderse sin la existencia de mecanismos de producción de sentidos, la educación, como práctica social y cultural, configura y se configura a partir de formas de comprender el mundo social de forma de hacerlo inteligible. Desde esta perspectiva, la educación -y en particular las políticas educativas- son entendidas como prácticas discursivas, esto es, como prácticas de significación. Esta mirada remece la noción de educación como parte de una "superestructura"así como también las lecturas deterministas que entienden la educación como resultado de un proceso causal. El énfasis aquí no está en la educación como producto -final, concluido, acabado- sino como práctica "generadora" de sentido. Desde esta mirada, entendemos las políticas educativas no sólo como conjunto de prácticas institucionales -que regulan las relaciones entre actores e instituciones- sino también como prácticas discursivas que producen los sistemas de razón que circulan entre las instituciones y las fronteras nacionales, estructurando el campo de la acción de lo posible, inscribiendo los principios de rendimiento y modos de subjetivación (Popkewitz \& Brennan, 2002).

Los efectos de sentido constituyen efectos de poder en tanto contribuyen a fijar posiciones específicas de sujeto, a fijar relaciones jerárquicas y producir identidades. Así, las políticas educativas no solo producen la organización formal o la estructura y contenidos de los currícula, sino también los sistemas de razón que ordenan, clasifican y jerarquizan las capacidades de los estudiantes y del profesorado; autorizan ciertos grupos de especialistas, al tiempo que desautorizan a otros; fabrican los “objetos" epistemológicos de los que hablan, a través de un léxico propio, con una jerga que no debe verse como una "moda" sino como un mecanismo muy eficiente de institucionalización y constitución de lo "real", que se exalta como referente (Da Silva, 1998).

Históricamente, la escolarización ha sido una práctica cultural mediante la cual los individuos se han podido comprender a sí mismos como personas con una "identidad nacional" y una ciudadanía. Este sentido de "pertenencia” y del "sí mismo" no constituye la manifestación de una cohesión social "natural" o geográfica, sino que depende de la producción de discursos lograda mediante una amalgama de tecnologías, ideas y prácticas sociales que forman a los individuos en torno a una narrativa colectiva. Precisamente, las narrativas que promueven los discursos estatales de política educativa producen sentidos que estructuran un recuerdo a través del cual los sujetos se sitúan a sí mismos en un "hogar". Recuerdos en torno al rendimiento escolar, la "calidad educativa", el "buen profesor" que instalan, en forma simultánea, formas de olvido.

2 Estas conceptualizaciones se inscriben en una epistemología postestructuralista, representadas por los Estudios Culturales y sintetizada en el llamado "giro lingüístico". 
El recuerdo no se entiende aquí como una labor de restauración, sino más bien de construcción: El pasado no está simplemente ahí, en la memoria, dado de una vez y para siempre, sino que tiene que ser articulado para convertirse en memoria. Más que un acto de recuperación, la memoria es siempre un acto de creación y transformación.

Así, la producción de recuerdo/olvido que instalan los discursos de política educativa constituye una práctica cultural que se inscribe en el marco de relaciones de poder, en un campo de lucha por imputar sentidos. No solo responden a construcciones locales, sino también a procesos globales. Por "global" no hacemos referencia a lugares geográficos sino a la circulación de narrativas universales que circulan a través de las fronteras nacionales, entre organismos estatales-gubernamentales, organismos internacionales de préstamo, la investigación social y educativa, etc. Discursos globales que permean las prácticas educativas nacionales.

Las profundas redefiniciones que ha sufrido el patrón de relaciones entre el Estado y la sociedad civil, en el marco de una creciente globalización de los mercados, han planteado importantes cambios en los sentidos y narrativas que circulan en torno al Estado y a la nación, con consecuencias para el discurso educativo quizás insuficientemente exploradas.

Contribuciones de la noción de subjetividad al análisis de los discursos públicos de política educativa en Chile

Desde el marco teórico-epistemológico anteriormente expuesto, se propone una reflexión que pretende poner en cuestión e interrumpir las lecturas dicotómicas y reduccionistas de los fenómenos educativos actuales que restringen la política a un tema de "gestión" más que a un discernimiento sobre los desafíos estratégicos, y del sentido de la educación.

Pensar la educación como experiencia intersubjetiva, esto es, como coproducción (en el mundo y con los otros), abre un campo de análisis que incorpora en la mirada al conjunto de las relaciones que convergen en el espacio escolar y pedagógico. Desde esta perspectiva, el aprendizaje es comprendido como la transformación del sujeto que emerge del espacio relacional. Estas relaciones están referidas a las que se establecen entre los sujetos que participan del proceso educativo (estudiantes, profesores, familias), así como también a las relaciones que se crean entre éstos y el contexto (barrio, la comunidad). En este sentido, pensar la educación desde este marco analítico supone una lectura holística e interdisciplinaria que incorpora en la mirada el conjunto de relaciones que se tejen entre las dimensiones sociales, culturales e histórico-políticas en juego, en cuya trama se van configurando los códigos y modos de convivencia, así como las imágenes y sueños de los sujetos participantes en torno a la experiencia educativa.

Esta propuesta epistemológica interrumpe las lecturas causales y reduccionistas de los fenómenos educativos actuales que restringen la política educativa actual a un tema de "gestión", perdiendo de vista la complejidad de los fenómenos educativos en su conjunto.

Es el caso de las políticas educativas orientadas por el principio de equidad, que son relatadas como "focalización de recursos en los segmentos más pobres de la población"; "discriminación positiva"; "compensación de las desigualdades económicas". Más allá de sus logros, las políticas de focalización, que entienden la desigualdad en términos 
estrictamente económicos, centran su accionar en "la inyección de recursos" sin llegar a interrogar las condiciones institucionales, sociales, políticas, económicas que producen la exclusión (mercantilización de la educación en una sociedad extremadamente segmentada, entre otros).

Del mismo modo, los discursos en torno a la "crisis de calidad de la educación" culpabilizan a los actores, interpretando o simplemente constatando el bajo rendimiento desde las condiciones de vulnerabilidad de los barrios, o desde las características -o carencias- de las familias. Así, se establecen relaciones causales entre pobreza y rendimiento, entre pobreza y deterioro del clima escolar, que justifican la desigualdad.

Estas lecturas simplistas reducen lo que se aprende en las escuelas a fragmentos separados, evaluables y comparables de conocimientos académicos. Su marco analítico invisibiliza las dimensiones vinculadas al contexto, ya que se trata de discursos que omiten en su argumentación los efectos que puedan tener sobre el rendimiento otras dimensiones relevantes para la experiencia educativa, como la pertinencia de las bases curriculares o los mecanismos de selección de estudiantes, etc.

Esta perspectiva, que define el rendimiento educativo en función de un conjunto cerrado y fragmentado de criterios aplicados a test, estrecha y empobrece el modo en que pensamos la educación, en tanto ignora las dimensiones sociales, éticas y estéticas de la experiencia de aprender, dando por supuestas muchas ideas problemáticas, tales como los propósitos de la educación o los puntos de referencia para definir "la" calidad en educación.

En este escenario, la noción de educación como acontecimiento intersubjetivo constituye una apuesta epistemológica que interrumpe esta lógica reduccionista, para dar lugar a un modo diferente de pensarla, un modo que no se agota en la mera repetición de lo mismo, ni en la reproducción del orden social, sino que, dando lugar a otros lenguajes, abre la posibilidad de comprenderla como fenómeno complejo.

La educación abordada desde su complejidad nos permite pensarla no como "producto" final cerrado en sí mismo, sino como creación incesante, en una red de relaciones en que se vinculan en convergencia y emergencia lo social, lo histórico-cultural, lo político, lo psíquico, lo orgánico y lo biológico.

También desde un abordaje interdisciplinario, la noción de política como proyecto de autonomía, complejiza la mirada para pensar la política educativa más allá de la gestión de recursos. Desde una perspectiva descentrada del sujeto psicológico y de modelos de conciencia, ésta permite incursionar los nexos posibles entre individuo y sociedad. Se trata de una noción que interrumpe las lecturas "dicotómicas" (micro-macro; individuo/ sociedad; etc.) dando cuenta del carácter "construido" que siempre tiene la organización social y nuestras formas de convivir.

Para esta propuesta que desplaza el foco de análisis del sujeto (considerado como individuo) al conjunto de relaciones y condiciones que lo "configuran", la subjetividad ya no puede ser entendida como una materia prima anterior a la vida social, sino más bien una construcción que se configura en relación al modo en que se organiza la sociedad $y$, en especial, al modo en que la política instituye esa organización social.

Esta perspectiva teórica y epistemológica abre un campo perceptivo para pensar y analizar los discursos públicos de política educativa más allá de los marcos regulatorios que instituyen o las asignaciones presupuestarias, sino como prácticas que producen los objetos de la reflexión organizativa e institucional. En este sentido, el centro del análisis 
son las narrativas que instalan los discursos de la política educativa, en tanto inscriben propósitos e intencionalidades, estableciendo distinciones, jerarquizaciones, valoraciones, calificaciones, que circulan entre y dentro de las instituciones, ordenando y prescribiendo las prácticas y los principios de acción y participación de los sujetos.

\section{REFERENCIAS BIBLIOGRÁFICAS}

Castoriadis, C. (1999). Figuras de lo Pensable. Buenos Aires: Fondo de Cultura Económica.

Castoriadis, C. (2003). La institución Imaginaria de la Sociedad. Volumen 2: El Imaginario Social y la institución. Buenos Aires: Tusquets.

Castro, E. (2004). El vocabulario de Michel Foucault. Buenos Aires: Universidad Nacional de Quilmes.

Da Silva, T. (1998). Cultura y currículum como práctica de significación. Revista de Estudios del Currículum, Volumen $\mathrm{N}^{\circ}$ 1. Madrid, Editoria Pomares, 59-76.

Deleuze, G. (1987). Foucault. Buenos Aires: Paidós.

Farina, C. (2005). Arte, cuerpo y subjetividad. Estética de la formación y pedagogía de las afecciones. Universidad de Barcelona: Tesis Doctoral Departament de Teoría i historia del l'Educació.

Flores, L. (2005). Subjetividad social y violencia. Rev. Pensamiento Educativo. Vol. 37. (Diciembre) pp. 198-212.

Foucault, M. (1990). Tecnologías del yo y otros textos afines. Barcelona: Paidós.

Foucault, M. (1992). Microfísica del poder. Madrid, La Piqueta. Tercera edición.

Foucault, M. (2002). Vigilar y castigar. Nacimiento de la prisión. Buenos Aires: Ed. Siglo Veintiuno.

Foucault, M. (2004). El orden del discurso. Buenos Aires: Tusquets Ediciones.

Foucault, M. (2002). La Arqueología del Saber. Buenos Aires: Siglo XXI.

Lechner, N. (2002). Las sombras del mañana. La dimensión Subjetiva de la Política. Santiago: LOM Ediciones.

Pardo, J. (1997). De cuatro formas que podrían resumir la filosofía deleuziana. En J. Aragües, Gilles Deleuze, un pensamiento nómada. Zaragoza: Mira.

Pérez, G. (2002). Entre el poder del discurso y el discurso del poder: Aproximaciones teóricas y metodológicas al estudio del discurso político. En A. Komblit, Metodologías Cualitativas en Ciencias Sociales. Buenos Aires: Biblos.

Popkewitz, T., \& Brennan, M. (2002). El desafío de Foucault. Discurso, conocimiento y poder en la educación. Barcelona: Pomares.

PNUD (2002). Desarrollo humano en Chile. Nosotros los chilenos: Un desafío cultural. Santiago de Chile.

PNUD (1998). Las paradojas de la modernización. Santiago de Chile.

Sobrero, V. (2011). Configuraciones de sentido en torno a la educación pública en Chile. Análisis de las continuidades y desplazamientos de sentido en torno a la educación pública en los discursos de política educativa pronunciados a partir de 1990. Tesis para optar al grado académico de Doctor en Ciencias de la Educación. Pontificia Universidad Católica de Chile. Santiago de Chile.

Terán, O. (1995). Michel Foucault: Discurso, poder y subjetividad. Buenos Aires: El cielo por asalto.

Varela, F. (2000). El fenómeno de la vida. Santiago: Dolmen. 
